\title{
A THERAPEUTIC CONTRIBUTION FROM THE CENTER FOR MENTAL HEALTH: MULTIPUSSE PSYCHOTHERAPY FOR NEUROTIC DISORDERS
}

\author{
Dr. Gabriel Lajús Barrabeitg $1 \bowtie$ (iD
}

${ }^{1}$ Doctor of Medicine, Doctor of Medical Sciences, Master in Psychiatry Social, 1st and 2nd Degree Specialist in Psychiatry, Diploma in Psychotherapy, Psychotherapist. Professor of Transactional Analysis at the East / Wind Institute of Canada. Full Professor and Senior Researcher at the University of Medical Sciences of Havana. Scientific Degree Advisor and Professor of Psychiatry and Medical Psychology of the Postgraduate and Research Department of the Victory Girón Faculty of Medical Sciences of said university in Cuba, Caribbean

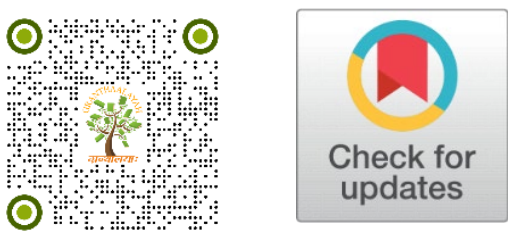

Received 20 November 2021

Accepted 16 December 2021

Published 26 January 2022

\section{CorrespondingAuthor}

Dr. Gabriel Lajús Barrabeitg Ph. D gabriellajusbarrabeitg@gmail.com

DOI 10.29121/jahim.v2.i1.2022.16

Funding: This research received no specific grant from any funding agency in the public, commercial, or not-for-profit sectors.

Copyright: (C) 2022 The Author(s). This work is licensed under a Creative Commons Attribution 4.0 International License.

With the license CC-BY, authors retain the copyright, allowing anyone to download, reuse, re-print, modify, distribute, and/or copy their contribution. The work must be properly attributed to its author.

\section{ABSTRACT}

Introduction: With more than 52 years dedicated to psychotherapy, the National Center for Mental Health applies a technique, which has its origin in the Soviet school.

Objectives: Establish a comprehensive relearning to produce profound changes in the personality and achieve the enrichment, growth, spiritual and human development of the subject.

Methods: Designed to work in a group of 30 previously selected patients taking into account the inclusion, exclusion and exit criteria, with the use of methods, resources and strategies in psychotherapy that work on the unconscious groups in the face of the fear reaction and motivation. applying different modalities of psychotherapy and multiple therapeutic tools that, with an integrative approach.

Results: Contribution of an autochthonous, Cuban psychotherapy technique, conceived intime, thanks to the work experience of prestigious professors; necessary for the combatants and applicable, furthermore, in the neurotic disorders of the rest of the population.

Discussion: The mental health of the combatants needs to be protected against the demands of the environment, which, as a social being, is kept in constant dialectical interaction. Have a psychotherapy model where its results have been evaluated for years by cohort studies that demonstrated $80 \%$ effectiveness or cure; growth, enrichment, spiritual and human development with great satisfaction for patients and families, constitutes a contribution to science.

Conclusions: Provided a new model of autochthonous psychotherapy, which avoids therapeutic and psychopharmacological dependence, favors personal development, manages to reinsert the patient early into the community, reduce the average stay and lower hospital costs.

Keywords: Psychotherapy, Group psychotherapy, Predispositions, Unconscious sets, Ustanovskas, Systemic approach, Soviet Marxist psychologists 


\section{INTRODUCTION}

Psychotherapy, in its different modalities, is expressed every time that the doctor in his professional management uses in a conscious and planned way, according to the problems of the patient, resources that act on him psychologically and aims to eliminate symptoms, modify patterns of inappropriate behaviour or maturing the personality, which expands or restores the creative adaptation of the individual to the environment. González (2008).

One of the many classifications of psychotherapies, divides them according to the objectives pursued into: suppressive psychotherapies (relieve symptoms), re educational psychotherapies (modify inappropriate behaviour patterns) and reconstructive psychotherapies (produce a global development of the personality). González (2008), Castro-López (1977), Castro-López (1982), Castro-López et al. (1988),

In the present work, given its objectives, only mention will be made of the autochthonous psychotherapy of Modification of Predispositions or Psychotherapy of a Systemic Approach, which includes the contributions of the school of Soviet Marxist Psychologists, so that the work focused on the Model of Multi-push Psychotherapy for Neurotic Disorders, which is the one provided by the National Center for Mental Health (CENSAM), which is why it constitutes the central axis of this issue.

The theoretical foundation of the first, the Predisposition Modification Psychotherapy, is based on the innovative conceptions of psychologists and other Soviet Marxist researchers about personality, its most relevant elements are the ustanovskas or predispositions in Spanish and their conceptions about motivation o reason. Castro-López (1977), Castro-López (1982), Castro-López et al. (1988),

The conception of the ustanovskas of Soviet psychology proposes the restructuring of a functional organization of the organized nervous system on the basis of the interaction of the congenital conditions of the individual with his environment (learning), which unconsciously predetermines his activity, whether cognitive, emotional, or conative. These ustanovskas therefore have a physiological basis and a psychological expression. Castro-López (1977), Castro-López (1978), Castro-López and Martínez (1981), Castro-López (1982), Castro-López et al. (1988)

The Marxist conception of the unconscious considers it part of consciousness, which is why consciousness is divided into self-consciousness, which is the knowledge of seeing the subject of its own activity and unconscious, constituted by habits and ustanovskas. The latter unconsciously determine the activity of the individual and in their specific aspects are known as attitudes, which will be governed by certain predispositions. Castro-López (1982), Castro-López et al. (1988)

Motivation is closely related to the and constitutes one of the fundamental aspects of modern Marxist Psychology of personality, dependent on the historical social development of the individual. Castro-López (1978), Castro-López and Martínez (1981), Castro-López et al. (1988)

The native technique of Professor Ph. D. Castro-López Ginard Hiram psychotherapy with a systemic approach or predispositions management, is based on motivation on the one hand and the modification of predispositions on the other, with the use of physiological and psychological resources that allow to establish a comprehensive relearning, which involves profound changes in the personality. The professor confirmed the hypothesis that all psychotherapy modalities exert their 
action either by modifying the attitudes or characteristics of the subject's personality or by reducing anxiety. Castro-López (1978), Castro-López and Martínez (1981), Castro-López et al. (1988)

The ustanovskas that appear before the fear reaction in front of psychotraumatic situations are the flight, the search for support and the need for recognition or social reaffirmation Castro-López et al. (1988) they are the tripod of the work in this therapy, which are psychotherapeutically worked to unlearn harmful behaviours and relearn healthy behaviours.

At the same time, in the course of the session, anxiety rises with various resources (handling silences, inflections and metal of the voice, use of non-verbal language, mimicry, pantomime, etc.), to the maximum tolerable by the group or the patient, with the aim of breaking the rational emotional barrier, which facilitates the self-conscious understanding of its characteristics. Castro-López (1977), CastroLópez (1978), Castro-López et al. (1988)

The professor conceived it for closed groups of up to 50 patients, during an hour and a half of therapy, to be worked on in the first level of care with a weekly frequency to achieve the fulfilment of the objectives of the five stages of treatment, with a total average duration of eight to 12 weeks. During the first 40 to 50 minutes the fundamental part of the technique is carried out, the modification of the predispositions. After a five- to 10-minute break, they start acting from the second inning, where Schultz's autogenic training is applied at its lower level, followed by group light hypnosis in which the necessary elements are reinforced. Castro-López (1977), Castro-López and Martínez (1981) Castro-López et al. (1988)

It is aimed at patients with neurotic functioning: neurotic disorders - formerly known as neurosis -, personality disorders in fundamentally reactionary crises, somatoform disorders and adjustment disorders. It does not include patients with mental retardation, psychosis, patients with moderate to severe arterial hypertension, or coronary heart disease.

Over the years, in psychotherapy, multiple schools and different modalities of its practice have emerged from Freud to the present day and, more and more new models of treatment emerge. Rodríguez (2016), Clavijo (2002), Saldivar, 1998; Martínez (2012), Berne (1961), Luria (1977) constituting another new one, the psychotherapeutic model bequeathed by the CENSAM, considered as the corporate author of this technique, which, due to the objectives pursued, classifies as a reconstructive psychotherapy.

In other words, the multi-push psychotherapy of the CENSAM Day Hospital service, arises from practical work experiences with groups of patients admitted to partial hospitalization, carriers of the group of pathological entities conceived within neurotic disorders, through the previous application, conscious and planned of a theory, the Modification of Predispositions or Systemic Approach psychotherapy adjusted to the secondary level of care in a therapeutic community regime, which, without having the intention of wanting to contribute a new psychotherapeutic alternative to the specialty, succeeded.

Given the characteristics of the missions carried out by most of the personnel who are assisted by CENSAM, which in addition to requiring special skills, at the same time, represents a group at risk of becoming ill due to chronic stress and maintained over time, The role demands discipline both in the country and abroad, insomnia and forced isolation, etc., in which the maintenance of the state of health is a priority and a requirement to fulfil the assigned missions. 
In summary, it can be argued that the emergence of Multi-push Psychotherapy for Neurotic Disorders is the result of the interest and expertise in psychotherapeutic work of different generations of prestigious national professors from CENSAM and other health institutions, added to the influences and Contributions from accredited foreign teachers from different latitudes, who contributed to its perfection and the greater effectiveness of the psychotherapeutic treatment in this outpatient service.

On the other hand, applying the law of the dialectic of transit by accumulation of quantitative changes, he determined the qualitative leap, to move on to a new psychotherapy with another rigor, demands and more ambitious, more complex, and extended work objectives, such as they will be reflected later in the development of this work.

So, the following scientific problem was posed.

How to contribute to the achievement of profound changes in the personality and personal and human growth of a population that requires special skills, which contribute to a better professional performance, quality of life, preservation, and restoration of mental health?

To solve this problem, the following objectives were outlined in each work meeting, with the psychotherapeutic model that was provided.

\subsection{OBJECTIVES OF THE PSYCHOTHERAPEUTIC MODEL}

1) Establish a comprehensive relearning, which involves the production of profound changes in the personality.

2) Facilitate the enrichment, growth, and spiritual and human development of the subject.

\section{METHODS}

It can be affirmed that this model of multi-push psychotherapy is the product of the dedication and skills in the psychotherapeutic work of generations of national teachers from this center, and the influence of teachers from other health centres in Cuba, who bearers of the knowledge of classical techniques, adjusting systemic approach psychotherapy to the Day Hospital Service and seeking an integrative approach, added to the influence and contributions of accredited foreign professors, applying the law of traffic dialectics, by accumulating quantitative changes the qualitative leap occurs, with the emergence of the new model that is described.

Methodologically, this model uses techniques, resources and strategies in psychotherapy, already described and applied by other schools, modalities and types of psychotherapy, which appear collected in both national and foreign literature and are part of the knowledge and skills acquired during professional practice of mental health personnel who practiced psychotherapy as a treatment modality in the CENSAM Day Hospital Service, for more than the last 40 years that were adapted to the individual needs of each group of patients and of the patient himself, without losing of view the support or theoretical foundation.

Theoretical basis originating in the Soviet school, based on work with the pathological predispositions that appear in the face of the fear reaction such as flight, the search for support and the need for recognition or social reaffirmation that causes the psychiatric symptoms of the disorders neurotic, which emerge during the session in the course of an incisive psychotherapy, raising anxiety levels in addition to the planned elevation with the resources and techniques that 
therapists use to achieve this same effect, to achieve the maximum levels of anxiety tolerable by the group, with the aim that their psyche break the emotional-rational or cognitive-behavioural barrier and manage to identify their behaviours and their relationship with the symptoms, even without wanting to do so, what passes from the unconscious to self-consciousness than with the iterative of psychotherapy the deconditioning of harmful behaviours is achieved and their change for healthier behaviours; that is, relearning occurs despite the resistance to change in the initial stages, which, thanks to the incisiveness of therapeutic management, leads them to replace unhealthy coping styles that cause symptoms, signs and suffering of their drama human; for healthier others, coping that as a pathological conditioning they have unconsciously repeated throughout their lives prisoners of the disease.

From the first psychotherapy session to the most advanced stages of treatment, they are trained with multiple techniques and resources to channel anxiety and their empowerment in techniques, knowledge and skills that modify their individual, family, and social functionality, which is equivalent to saying that a better creative adaptation to the environment is achieved.

It was designed to work in a group of 30 patients previously selected taking into account the inclusion, exclusion and exit criteria, with the use of methods, resources and strategies in psychotherapy that work the unconscious sets against the fear reaction and motivation, using different psychotherapy modalities and multiple therapeutic tools that with an integrative approach, the contribution of a new psychotherapy with another rigor, demands and objectives was achieved throughout these years of practice, explaining its departure, by applying the law of dialectics of the transit through accumulation of quantitative changes to the qualitative leap, resulting in a new model of psychotherapy with more ambitious objectives.

As mentioned, the following inclusion, exclusion and exit criteria were established for the incorporation and / or permanence of the patients in the work group.

\subsection{INCLUSION CRITERIA}

1) Patients with Neurotic Disorders (neurotic disorder, which includes the group of previously called neuroses, personality disorders in crisis, somatoform disorders, adjustment disorders)

2) They were also included (addictive disorders, violent patients as victims or perpetrators of domestic violence, sexual dysfunctions of any etiology).

\subsection{EXCLUSION CRITERIA}

Instead, the exclusion criteria established were those listed below.

1) Psychiatric pathologies such as: psychosis, mental retardation of any degree, patients with brain organicity and pre-psychotic patients.

2) Organic pathologies such as: coronary heart disease and arterial hypertension in the degrees of moderate to severe.

\subsection{EXIT CRITERIA}

They are established, before the appearance of some of the following pathological conditions once the treatment has started.

1) Patients who make psychotic incursions or trigger frank psychotic pictures. 
2) Patients who show little motivation for change and / or low levels of suffering in daily practice.

3) Appearance during the treatment of any medical condition that contraindicates psychotherapy.

4) Violation of the disciplinary regulations of the service.

It is good to emphasize that patients with ischemic heart disease and moderate to severe arterial hypertension are ruled out, because the anxiety itself necessary for psychotherapeutic work, the anguish they face in the treatment process, with the implicit discharge of Sympathetic mimetic amines by the sympathetic nervous system, could decompensate their underlying disease or trigger complications that could leave a disability as a sequel and, in the worst case, cause death.

Under the respect of the ethical principles of rigor, all patients are informed of the characteristics of the work with this model of psychotherapy, the incisiveness of the same so that it is not interpreted as aggression and, in this way, their consent is obtained in writing informed.

\section{RESULTS}

Over the years, the integrative vision and the contributions made to the Systemic Approach Psychotherapy that were previously described, gave way to a new modality of deep psychotherapy, that of multi-push, with more ambitious objectives that achieves a better organization and functionality of the patient's personality, which translates into maturation, growth, enrichment and spiritual and human development that allows him to achieve greater and better satisfaction of the demands of life, greater social adaptability, conflict resolution through learning skills communicational social, for anger management, for conflict resolution, guaranteed by more assertive and less tacit thoughts and behaviours.

In addition, it manages to provide them with knowledge in various areas of knowledge such as drug addiction and its consequences, violent behaviours in the various scenarios of daily life and understanding of sexuality, all of which constitutes a strength that they later multiply in their family, in the community and guarantees them to regulate their behaviour and avoid pathological conditions.

It is a technique that responds to the interests of the military institution, since far from causing the combatant to be discharged due to their lack of aptitude for the role, they manage to be reinserted into their military community of origin, which guarantees the retention of the strength, especially from prepared, experienced, and expert subjects, needed in an organ that requires special skills for almost all its positions.

It is a legitimately Cuban psychotherapy that adds to the list of autochthonous psychotherapies, which collects the wealth of professional experience in this activity of several generations of psychiatrists who have dedicated themselves and / or dedicate themselves to the care of patients of a functioning level. neurotic, so it represents a theoretical, practical, and methodological contribution to science, achieved by CENSAM.

\section{DISCUSSIONS}

\subsection{DESCRIPTION OF THE TECHNIQUE}

For your better understanding, the description of the new psychotherapy model that was provided is organized below. 


\subsubsection{THEORETICAL BASIS OF MULTI-PUSH PSYCHOTHERAPY FOR NEUROTIC PATIENTS}

It begins by underlining that man separated from his social context does not develop as a person. It is often heard that man is a social being, and it is not possible to form an adequate explanation, that man is a product of society, that he has a historical-cultural determination, but that he also needs it to develop fully, to form his personality. Castro-López et al. (1988), Núñez-Villavicencio (1987a), NúñezVillavicencio (1987b).

The dialectical materialist conception of the formation and development of the personality expresses the unity between the internal conditions of development or internal environment and the external conditions of development or external environment, which means the unity between the biological and the social. In this way, the biological factor contributes the anatomical-physiological premises to the development of the personality, the CNS and its material base, the brain, and the social factor constitutes the source from which the experience of the individual (learning) is nourished, which It occurs in a particular way in each person, in each of the stages of development. Castro-López et al. (1988), Núñez de Villavicencio, Núñez-Villavicencio (1987a), Núñez-Villavicencio (1987b) Moreno (2003), Alvarez (2001), Bello and Casales (2003)

The behaviour of the subject at each moment allows inferring the psychological characteristics of his personality, it is, until now, the only objective method for its study, since the psychic cannot be seen, heard, or touched. (Núñez-Villavicencio (1987a), Núñez-Villavicencio (1987b)For example, when any element of the personality is manifested, let us say character, in some of its properties such as honesty, it does not do so in isolation, but ideas, aspirations, motivations, interests are expressed through it. , values, etc., of the personality. Núñez-Villavicencio (1987a), Núñez-Villavicencio (1987b) Personality is a complex and monolithic system. When a subject act, he responds with his personality, which is an indivisible, unique and unrepeatable unit or individual. Its elements are in unity and strong interaction, they are only separated for study and to be able to act on them. Hence, the personality has a systemic character. Núñez-Villavicencio (1987a), NúñezVillavicencio (1987b) Moreno (2003), Alvarez (2001), Moreno (2003) Campo and Orosa (2004).

Therefore, from this philosophical position, the personality is a system and as such must be analysed according to the systemic approach. This means that in the study of personality, its components must be clarified: structure, interrelations, its functions and the dynamics of its formation and development. Núñez-Villavicencio (1987a), Núñez-Villavicencio (1987b) Moreno (2003), Alvarez (2001)None of these factors, by themselves, can determine the development of the personality, only thanks to activity and communication can such development occur, that is, through the interrelation between the internal and the external. Núñez-Villavicencio (1987a), Núñez-Villavicencio (1987b) However, we must bear in mind that the personality, like any system, is subject to the principle of development, which implies a constant process of change and transformation that allows the transition to higher levels of organization. Núñez-Villavicencio (1987a), Núñez-Villavicencio (1987b) Moreno (2003), Alvarez (2001), Moreno (2003), Campo and Orosa (2004)

These more current knowledge of the personality justifies the objectives outlined in this treatment model, because according to already expired thoughts, the personality was information from the early ages of life to 25 years and since then it has remained unchanged throughout life. 
The theoretical foundation is found, in the same way cantered, on the innovative conceptions of psychologists and other Soviet Marxist researchers on personality, its most relevant elements are the ustanovskas and their conceptions on motivation; the Marxist conception of consciousness, which divides it into selfconsciousness and the unconscious; the elevation of anxiety levels, with the use of different resources, with the aim of causing the breakdown of the cognitivebehavioural barrier, and gradually achieving the unlearning of disturbed behaviours and the relearning of new, healthier ones, As previously stated when analysing the school of Marxist psychologists and the technique of psychotherapy with a systemic approach.

\subsection{WORK TEAM}

The members of the work team that should be permanent, need to have an adequate preparation in psychotherapy and a versed knowledge of the technique and be aware of the moments in psychotherapy, as well as be knowledgeable experts of most of the techniques, resources and strategies in psychotherapy in general, the various schools that have emerged from Freud to the present and their fundamental modalities; They must have work discipline, a sense of belonging, group cohesion, communication skills, as well as a work style to constantly model healthy behaviours in front of patients, maintaining a professional and therapeutic relationship in all the settings in which they move with patients, preserving professional and emotional distances with them.

As in all psychotherapy, the work team establishes a previous contact with the patients, where the strategies to be followed in the session are outlined and, another, after the session, where the results obtained, successes, mistakes, handling are analysed. anticipated, breaking of silences, mistakes made, iatrogenesis, role of the co-therapists, etc., also ensuring that the patient has not felt attacked by the therapists, since it is an incisive therapy.

The team is made up of a Bachelor of Nursing as a key element since she is the one who stays most of the time with the patients, has greater knowledge of each one and the group in general, so she is the one who provides feedback to the rest of the team in information about the group and about the patients. It is also made up of two Psychiatrists, one or two Graduates in Psychology, and an Occupational Therapist, and there are also undergraduate and graduate students, fifth-year medical students, Health Psychology students, and Psychology Specialty students. of Health, Residents of Psychiatry and any other professional from another center who is in training of this model.

\subsection{ORGANIZATION AND FUNCTIONALITY OF PSYCHOTHERAPY}

1. Prior evaluation of future income by the work team, in order to determine the degree of suffering from the human drama and the motivation for change. If admission is decided, the disciplinary regulations of the service are made known to them and the therapeutic contract is made, establishing responsibilities, agreements and an appointment is made for their incorporation into the group.

The clinician is referred for evaluation and indication of essential supplements and how many derive from them, ruling out clinical pathologies that could also contraindicate therapy. 


\subsection{MODALITIES}

1) This model, although conceived to work in psychotherapy groups, can also be used in individual, family, couple, and sexual work.

2) We work with groups of 30 patients, and although there could be a greater number, almost always 20 places have been limited by particular characteristics of the organ, since the number of individuals for admission decreases with certain recurrence, not due to the absence of objective needs for care. mental health, but rather by prioritizing the specific work, management decisions, etc., which can ruin, with a demand much lower than the supply in the case of larger groups, with the increase in the cost of the service provided and the consequent affectation of hospital indicators, particularly the occupational index, required in health institutions for each service.

3) We work with semi-open groups, which constitutes an opportunity that in turn becomes a threat, because the entry and exit of patients, to and from the group, can be weekly, which enriches it with the incorporation of new cases with different dynamics; but at the same time, it imposes a greater challenge on therapists, as they have to work with subjects who are in different stages of psychotherapeutic treatment, each of which has its specific work objectives to fulfil, which requires training.

4) The total duration of treatment has an average time of three months or 12 weeks, but depending on individual needs, it may end weeks before or weeks after the 12 established, and then be reintegrated to their community of origin. In addition, they are evaluated again one month after hospital discharge within the group that is in session in the morning, to later be evaluated again after one year of hospital discharges, at which time the medical discharge could be decided.

5) The duration of the sessions is $2 \frac{1}{2}$ hours, with a first entry of $1 \frac{1}{2}$ hours, in which the modification of predispositions supported by motivation is worked, and a second entry, after 10 to 15 minutes of break, dedicated to reducing or calm the anxiety levels reached in the previous entry, and to send sedative messages, in correspondence with the operations carried out in the first entry with an average duration of 45 minutes.

6) Patients are imposed by the dynamics of work, the punctual start of activities, the prohibition of joining the workplace if they travel with thirdhand tobacco smoke; do not knock or knock on the door when it is closed, know that they can leave the therapy session if they wish, but cannot reenter; that they need to evacuate the emunctories before entering the workplace to avoid the distraction of the group with their departure; that they can feel hostile and very anxious in the heat of psychotherapy, and with the progress of the treatment, since a behaviour and attitude is now ego dystonic, which was previously ego-syntonic and because what was previously unconscious would prevail in self-awareness, etc.

7) You work in therapy, the two sessions of the day. The mornings, intended for psychotherapies, which are colloquially called by the group of therapists "main course", beginning on Mondays with the community meeting and on Tuesdays with psychotherapy per se. In the Wednesday session, depending on the needs of the group, work is done on therapeutic debate cinema, debate book or psychodrama, which is decided by the work team; like 
Thursday, which is dedicated to either movement therapy or the use of psycho dramatic techniques, or participatory techniques. Friday is reserved for a recreational activity, also therapeutic inside or outside the center with a representation of the therapeutic team.

On the other hand, the afternoon is destined, for the also called, colloquially "complementary therapies", in which, without losing the theoretical basis of the model, didactic resources are used aimed at training in social skills (communication-relationship), in which Communication Skills (conversation, persuasion), Trust Skills (selfesteem, self-control), Connection Skills (empathy, presence), training in the management of the Tacit, training in the management of Assertiveness and training in the management of the wrath.

In addition, they are enriched with other knowledge, during driving, with also didactic resources, on issues of sexuality, domestic violence, and drug addiction, which are options to choose for themselves on a weekly basis. Other complementary therapies, also used in the afternoon, are Pict therapy, music therapy, Hata Yoga, Tibetan Rites, philosophical reflections, among others, depending on the individual needs of the group. In other words, the various forms of group psychotherapeutic work are included in a treatment program, which is flexible, to guarantee its full compliance depending on the needs of the group of patients.

On the other hand, it is good to say that, in the afternoon hours, they are also valued by the Traditional Natural Medicine Specialist, who decides what treatment they are going to follow from this specialty; nor does it lack, in this schedule, the self-evaluation of the patients and the weekly physical preparation.

It should be mentioned that, in the afternoon hours, family, couple and / or sexual psychotherapy sessions are held, depending on the needs of each case. At the same time, the knowledge of the patient and its dynamics is deepened, through interviews with their relatives, bosses, and acquaintances, achieving management of the family, work and social environment, which also contribute to overcoming conflicts in these areas and, therefore, to improve the quality of life of these people.

In the same way, they are given an individual visit pass which, in the second week of treatment, is for everyone; to later, only be carried out by decision of the therapeutic team for the punctual handling of some private situation that justifies it; when they request it, although when they handle some difficulty that could be worked on in the group, they are encouraged to do so in it. However, even though this individual treatment option is not excluded, it is a matter of ventilating the problems, fundamentally, in the group of patients.

8) First entry: The first entry of the first morning psychotherapy session can begin with a specific or nonspecific warm-up, in it the group is made up, the pathological predispositions are worked on in the face of the fear reaction (flight, search for support and need for recognition or social reaffirmation) supported by motivation, with the aim of unlearning harmful behaviours and relearning healthy behaviours. The week goes by in this way, according to the flexible schedule envisaged for the Day Hospital service.

In addition, it delves into the learning of the tools that are being used to reduce anxiety levels and, at the same time, the learning of these during the second entry in each session, because when their pathogenic 
conditioning is worked, when the predispositions disappear pathological, they remain, illustratively, as "a chair with a missing leg", added to the intense anguish generated by the dissonance of the new learned behaviour with the predisposition; that, by causing intense anguish, can lead them to reuse those previous abnormal conditioning.

9) Role of the therapist and Management Style: The role of the therapist is very active, it is a management style defined by the therapeutic process itself, which moves between the more-less directive with the use of all the resources at its disposal. reach to raise the level of anxiety to the maximum tolerable by the group, through surprise, use of mimicry, pantomime, the use of non-verbal language more perceptible by self-awareness; management of silences, metal, intonation, cadence and inflections of the voice, etc., with the aim of breaking the rational emotional barrier; way of taking pathological predispositions from the unconscious to selfconsciousness, which prevents the subject from defending himself, looking for justifications, etc., in the face of their absurdity.

10) Second entry: After a break of 10 to 15 minutes, the second entry begins, with one of the following practices, depending on the level of cognitiveaffective-volitional resonance that the group reached during the first entry.

Among them, the following can be used: Schultz's Autogenous Relaxation followed by a collective light hypnosis, or the Jacobsom Relaxation method, Relaxation with two voices which is an indigenous psychotherapy technique, guided imagery, healing visualizations, meditation, emotional liberation exercises or tapping, breathing exercises by Bilaiev and Lowen, among others; those that at the same time, learn and incorporate for life, as resources to dispel anxiety.

\subsection{WORK STAGES OF THE MODEL AND ITS OBJECTIVES}

The model includes three work stages, each one with its average time and work objectives, so you should not move from one stage to the next, without first having completed these.

Some objectives, due to their importance in treatment, are repeated in subsequent stages, in order to reinforce the new coping styles and conditioning, compared to the previous ones that were not healthy and, now dissonant in the face of the new attitude and pathological predisposition that it can pulse for unchained, until it is extinguished in front of the repetition of the new attitude.

\subsubsection{FIRST STAGE}

The one that has a duration of two weeks and as objectives the following.

1) Structure the group of patients.

2) Delimit the responsibilities in therapy.

3) Know the method of work that they are going to assume.

4) Expand the knowledge of the characteristics of the patients.

5) Motivate patients. 


\subsubsection{SECOND STAGE}

It lasts for five weeks, and the following are the objectives.

1) Increase knowledge of the characteristics of patients.

2) Work the three ustanovskas when they appear, as they never come alone.

3) Get them to identify the consequences of their attitude and their expression in the cognitive, affective, and conative aspects.

4) Achieve self-conscious understanding of your predispositions.

5) Perfect the knowledge, creation of skills and use of the techniques used in the second entry.

\subsubsection{THIRD STAGE}

It also has a duration of five weeks and as objectives the following.

1) Continue working the predispositions or ustanovskas.

2) Continue the identification of the consequences of their pathological attitudes and their expression in the cognitive, affective, and conative aspects.

3) Achieve self-conscious understanding of your predispositions.

4) Train the patient in social skills, knowledge of sexuality, drug addiction and domestic violence.

5) Perfect the learning, skills and use of the techniques used in the second entry.

6) Recognize the dissonance and danger, between your new attitude and predispositions.

7) Consolidate the achievements and prepare them for social reintegration.

The modality of Multi-push Psychotherapy for Neurotic Disorders practiced at CENSAM allows the patient to be endowed with a wide arsenal of resources, skills and new knowledge that guarantee a better creative adaptation to the environment, to be able to channel anxiety, and to improve interpersonal relationships. that it can be affirmed that an enrichment, growth, and spiritual and human development of the subject is achieved, which contributes to a higher quality of life.

The model has been practiced systematically for 16 years, in which training has been carried out for Specialists in Psychiatry and Graduates in Psychology from the center itself, as well as Residents and Specialists in Psychiatry from military institutions from the "Luís Dias Soto" Hospital and the Military Hospital "Carlos J. Finlay".

From this model, training offers are prepared with the realization of theoretical-practical courses in a Community Mental Health Center outside CENSAM, with a weekly meeting, with a real group of 20 patients for 12 weeks.

This model of psychotherapy has been exposed in two international scientific congresses PSICOHABANA 2018 and PSIQCUBA 2019, in satellite events within the framework of two international psychotherapy symposia held in Cuba and, in addition, it was taught in a post-congress course, with broad national and foreign participation and, the recommendation by the audience, of its publication for greater international visibility.

In this way, the scientific problem was answered and ended with the following conclusions. 


\section{CONCLUSIONS}

The multi-push psychotherapy model for the treatment of neurotic functioning level patients is an autochthonous modality of psychotherapy that represents a contribution to science and the specialty of the National Center for Mental Health of MININT, an institution that is its corporate author; that achieves profound changes in the personality with a better creative adaptation to the environment and the establishment of a comprehensive relearning, enrichment, growth, spiritual and human development of the subject.

It consists of a comprehensive and intensive psychotherapeutic model, perhaps somewhat exhausting for therapists, that in studies carried out over years and in cohort studies, $80 \%$ of these patients have been rehabilitated or cured, which avoids therapeutic dependence or psychopharmacological, achieves early social reintegration into his community, decreases medication and the average length of stay, lowering treatment costs; therefore, it was decided to socialize the psychotherapy model with its publication, practice and offers of training courses aimed at the new generations of Cuban and foreign psychotherapists and members of the mental health team.

\section{CONFLICT OF INTERESTS}

None.

\section{ACKNOWLEDGMENTS}

None.

\section{REFERENCES}

Álvarez, R. (2001). Comprehensive General Medicine Topics (I). Health and Medicine. Havana, Cuba : Medical Sciences Editorial.

Bello, Z., Casales, J. C. (2003). (compilers) General psychology. Havana, Cuba : Editorial Félix Varela.

Berne, E. (1961). Transactional Analysis in Psychotherapy. New York, Grove Press, Inc.

Campo, D. \& Orosa, T. (2004). Introduction to Psychology. Havana, Cuba : Editorial Félix Varela.

Castro-López, H. (1977). Criteria For Individual Psychotherapy. Rev. Hosp. Psiq. From Havana. Extraordinary Supplement, 28(1), 155.

Castro-López, H. (1978). Bases for a Highly Advantageous Psychotherapy Technique In Our Environment. Rev. Hosp. Psiq. of Havana, 45(1).

Castro-López, H., Martínez, A. M. (1981). Criteria On The Usefulness Of A Simple

Psychotherapeutic Technique In Psychiatric Care. Rev. Hosp. Psiq. De La Habana, 22(4), 619.

Castro-López, H. (1982). The Mental Health Dispensary. Havana, Cuba : Present in Psychiatry, 3(3), 9-119.

Castro-López, H. (1988). Psychotherapy. Havana, Cuba : Medical Sciences Editorial. Castro-López, H., Barrientos, G., Bustamante, J. A., Pérez, J., Arés O., Rodríguez R., Pérez, R. (1988). Psychotherapy. Havana, Cuba : Medical Sciences Editorial.

Clavijo, A. (2002). Crisis, Family and psychotherapy. Havana, Cuba : Medical Sciences Editorial.

González, R. (2008). Current Basic Psychiatric Clinic. Havana : Medical Sciences Editorial, 152-160. 
Luria, A. R. (1977). The Upper Cortical Functions of Man. Havana, Cuba : Editorial Orbe.

Martínez, C. (2012). Family Health. Havana, Cuba : Technical Scientific Editorial.

Moreno, M. J. (2003). Psychology of Personality. Havana : Editorial Pueblo y Educación.

Núñez-Villavicencio, F. (1987a). Medical Psychology (I). Havana, Cuba : Editorial Education.

Núñez de Villavicencio, F. (1987b). Medical Psychology (II). Havana, Cuba : Editorial Education.

Núñez de Villavicencio, F. (2001). Psychology and Health. Havana, Cuba : Medical Sciences Editorial.

Rodríguez, R. C. (2016). Large Group Psychotherapy, Origin And Development in Cuba. Havana, Cuba : Technical Scientific Editorial.

Zaldívar, D. (1998). Alternatives in Psychotherapy. Havana, Cuba : Editorial Academy. 